\title{
Sitosterolemia: A Rare Case with Broad Implications
}

Zed Seedat $^{*}$, Gopika Dasari², Seth Baum ${ }^{3}$

${ }^{1}$ Florida Atlantic University Charles E. Schmidt College of Medicine, Boca Raton, FL. ${ }^{2}$ Florida Atlantic University Charles E. Schmidt College of Medicine, Boca Raton, FL. ${ }^{3}$ Florida Atlantic University Charles E. Schmidt College of Medicine, Boca Raton, FL

*Corresponding Author: Zed Seedat, Florida Atlantic University College of Medicine Internal Medicine Residency Program 777 Glades Road, BC-71 Rm 335 Boca Raton, Florida, 33431

Received Date: March 09, 2021; Accepted Date: April 09, 2021; Published Date: April 16, 2021

Citation: Zed Seedat., Gopika Dasari., Seth Baum., (2021) Sitosterolemia: A Rare Case with Broad Implications. J. Clinical Cardiology and Cardiovascular Interventions, 4(8); Doi:10.31579/2641-0419/151

Copyright: () 2021 Zed Seedat, This is an open-access article distributed under the terms of the Creative Commons Attribution License, which permits unrestricted use, distribution, and reproduction in any medium, provided the original author and source are credited.

\section{Abstract}

Sitosterolemia is an ultra-rare autosomal recessive dyslipidemia characterized by mutations in genes encoding the ATP-binding cassette (ABC) G5/8 transporters. We describe the case of a 20-month-old female presenting with xanthomas and serum low density lipoprotein cholesterol of $657 \mathrm{mg} / \mathrm{dL}$. Diagnostic workup revealed a previously undescribed sitosterolemia-causing mutation. After elimination of dietary sterols and initiation of ezetimibe therapy, the patient's xanthomas resolved, and serum low density lipoprotein cholesterol was reduced to $104 \mathrm{mg} / \mathrm{dL}$. Importantly, pathologically elevated serum phytosterols were found in each of the proband's heterozygous parents. Elevated phytosterols, an established cause of atherosclerosis, are typically unrevealed by standard lipid testing. As heterozygous mutations for ABCG5/8 are relatively common, this has implications for a broader population than the ultra-rare sitosterolemia cohort. Thus, insights gleaned from this case highlight underappreciated matters in the prevention of atherosclerotic disease in both heterozygous and homozygous carriers alike.

Keywords: sitosterolemia; genetics; cholesterol; coronary artery disease; low-density lipoprotein cholesterol

\section{Abbreviations}

$\begin{array}{ll}\text { ABC } & \text { : ATP-binding cassette } \\ \text { ALT } & \text { : Alanine transaminase } \\ \text { AST } & \text { : Aspartate transaminase } \\ \text { ASCVD } & \text { : Atherosclerotic cardiovascular disease } \\ \text { GC/MS } & \text { : column gas liquid chromatography/mass } \\ & \text { spectrometry } \\ \text { HDL-C } & \text { : high density lipoprotein cholesterol } \\ \text { LDL-C } & : \text { low density lipoprotein cholesterol } \\ \text { NPC1L1 } & : \text { Niemann-Pick C1-Like 1 } \\ \text { TG } & : \text { Triglycerides }\end{array}$

A 20-month-old girl presented to our preventive cardiology/lipidology clinic following an 8-month history of xanthomatous lesions on her buttocks and in her popliteal creases (figures 1-2). Both pediatrics and dermatology had identified the lesions as xanthomas and accordingly ordered a lipid panel. The patient's cholesterol levels were severely elevated, leading her clinicians to seek our input. The patient's history was significant for normal growth and development and the absence of any observed exertional symptoms. Family history was remarkable for the absence of premature vascular disease. Physical examination revealed xanthomas in popliteal creases, and on the ankles and buttocks; corneal arcus and xanthelasmas were absent. Cardiac, pulmonary, and rheumatologic examinations were normal. Splenomegaly was absent.
Homozygous and heterozygous familial hypercholesterolemia, sitosterolemia, and cerebrotendinous xanthomatosis comprise the differential diagnosis for pediatric patients presenting with xanthomatous disease [1]. Neurologic findings were absent; thus, cerebrotendinous xanthomatosis was highly unlikely. As familial hypercholesterolemia is nearly always autosomal dominant, while Sitosterolemia is always autosomal recessive, the absence of a family history of ASCVD significantly favors the diagnosis of sitosterolemia.

A lipid panel following the identification of xanthomas revealed: total cholesterol $725 \mathrm{mg} / \mathrm{dL}$, low density lipoprotein cholesterol (LDL-C) 657 $\mathrm{mg} / \mathrm{dL}$, high density lipoprotein cholesterol (HDL-C) $44 \mathrm{mg} / \mathrm{dL}$, and triglyceride (TG) $118 \mathrm{mg} / \mathrm{dL}$. Complete blood count revealed microcytic anemia. Reticulocyte count, lactate dehydrogenase, AST, ALT, total bilirubin and haptoglobin were within normal limits. Carotid artery duplex ultrasound and echocardiogram were unremarkable.

Targeted lipid gene sequencing and column gas liquid chromatography/mass spectrometry (GC/MS) testing for serum sterol concentrations were obtained on the patient and both parents. Compound heterozygous coding mutations in ABCG5 (R408X and W461R mutations) were identified in the proband. The previously undescribed W461R mutation was also identified in the patient's father, while the R408X mutation was present in the mother. The patient's phytosterol levels were markedly elevated with beta-sitosterol and campesterol above the detectable limit of $>3 \mathrm{mg} / \mathrm{dL}$ (normal, $<0.8 \mathrm{mg} / \mathrm{dL}$ and $<1.03 \mathrm{mg} / \mathrm{dL}$ respectively); lathosterol and desmosterol were normal at $0.11 \mathrm{mg} / \mathrm{dL}$ (normal, $<0.81 \mathrm{mg} / \mathrm{dL}$ ) and $0.13 \mathrm{mg} / \mathrm{dL}$ (normal, $<0.35 \mathrm{mg} / \mathrm{dL}$ ) 
respectively. Significant elevations in serum beta-sitosterol and/or campesterol levels were found in both parents. It is important to note that LDL-C was not significantly elevated in either parent (Table 1).

\begin{tabular}{|c|c|c|c|}
\hline & Proband & Father & Mother \\
\hline ABCG5 Genotype & $\begin{array}{l}\text { R408X and } \\
\text { W461R }\end{array}$ & $\begin{array}{c}\text { W461R } \\
\left(\mathrm{NM} \_022436.2: \mathrm{c} .131 \mathrm{~T}>\mathrm{A}\right)\end{array}$ & $\begin{array}{c}\text { R408X } \\
(\mathrm{NM} \text { _022436.3:c.1222C }>\mathrm{T})\end{array}$ \\
\hline Total Cholesterol (mg/dL) & 725 & 128 & 206 \\
\hline HDL Cholesterol (mg/dL) & 44 & 51 & 70 \\
\hline LDL Cholesterol (mg/dL) & 657 & 54 & 113 \\
\hline Triglycerides (mg/dL) & 118 & 114 & 114 \\
\hline Lathosterol (mg/dL) & 0.11 & 0.16 & 0.18 \\
\hline Desmosterol (mg/dL) & 0.13 & 0.09 & 0.12 \\
\hline Beta Sitosterol (mg/dL) & $>3$ & 0.85 & 1.23 \\
\hline Campesterol (mg/dL) & $>3$ & 0.92 & 1.79 \\
\hline
\end{tabular}

Phytosterol Normal Ranges: Lathosterol $<0.81 \mathrm{mg} / \mathrm{dL}$, Desmosterol $<0.35 \mathrm{mg} / \mathrm{dL}$, Beta Sitosterol $<0.80 \mathrm{mg} / \mathrm{dL}$, Campesterol $<1.03 \mathrm{mg} / \mathrm{dL}$. Table 1: Genetic, lipid and serum sterol screening.

Prior to genetic assessment, the patient had initially been given a provisional diagnosis of homozygous familial hypercholesterolemia. Pending evaluation at our clinic, she was advised to make dietary changes including eliminating pizza, cheese, and meat [2]. Six weeks later, the patient's LDL-C level decreased approximately $50 \%$ to $381 \mathrm{mg} / \mathrm{dL}$.

After definitively (genetically) diagnosing sitosterolemia, we advised the patient's parents to further modify her diet by eliminating all phytosterolrich food. Ezetimibe $5 \mathrm{mg}$ daily was also initiated [2]. Given the absence of exertional symptoms, further imaging with CT coronary angiography was not performed.

Several weeks after the patient had made stringent dietary changes and started ezetimibe $5 \mathrm{mg}$ daily, a repeat lipid panel revealed marked reductions in total and LDL cholesterol, $153 \mathrm{mg} / \mathrm{dL}$ and $104 \mathrm{mg} / \mathrm{dL}$ respectively. Additionally, the patient's cutaneous xanthomas resolved.
Because of socio-economic challenges and her parent's philosophical reservations regarding prescription medications, the patient's ezetimibe therapy was stopped, and she has not yet returned to the clinic. The patient's family has been repeatedly contacted and strongly encouraged to resume therapy. Her parents have also been counseled to undergo their own cardiovascular consultations for lipid management and risk reduction.

\section{Discussion}

Sitosterolemia is an ultra-rare autosomal recessive lipid disorder caused by mutations in the ATP Binding Cassette (ABC) transporters G5/8 [3]. Present in small intestine enterocytes and biliary tract epithelial cells, these $\mathrm{ABC}$ transporters participate in the efflux of both cholesterol and the biochemically similar dietary phytosterols, including sitosterol and campesterol (figure1,2and 3) [3]. 


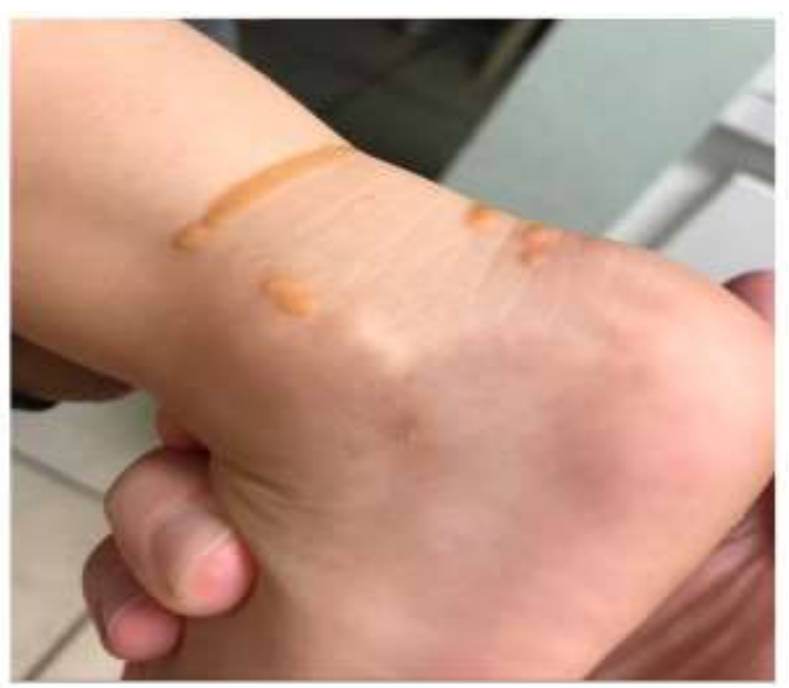

Figure 1: Xanthomatous lesions over right ankle. Classic appearing pediatric xanthomas are seen.

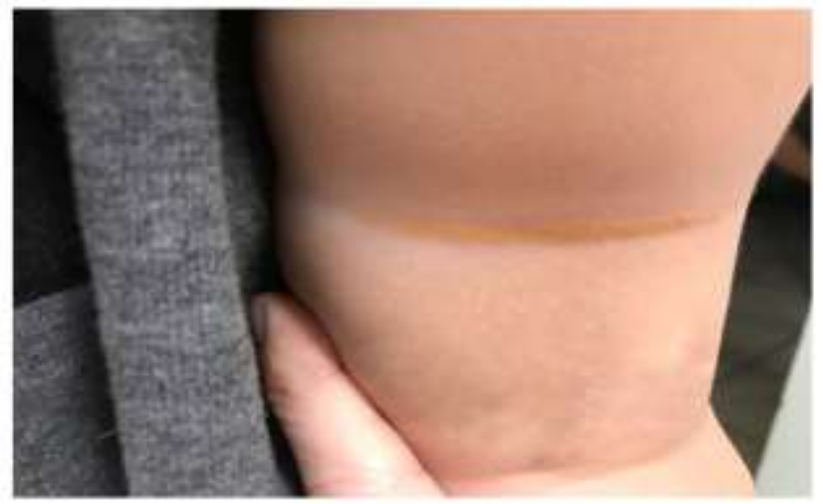

Figure 2: Xanthomatous lesion within right popliteal crease. A less commonly appreciated linear appearing xanthoma is shown in this image.

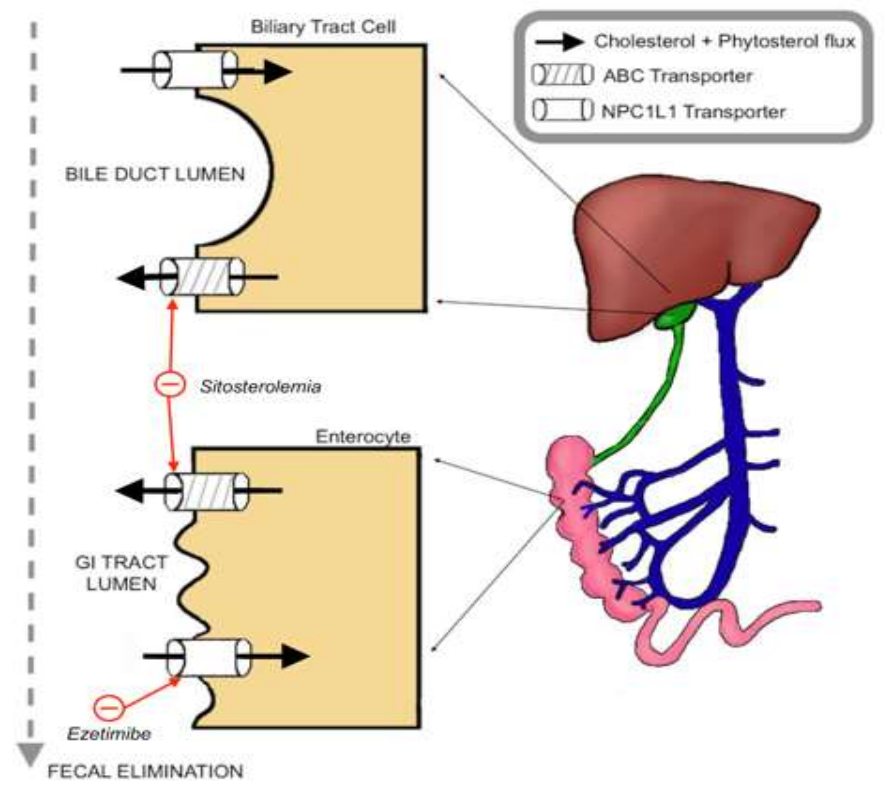

Figure 3: Cholesterol and phytosterol flux pathways across functional ABC and NPC1L1 transporters. A schema depicting the crucial but underrecognized pathway of cholesterol and phytosterol absorption and excretion is seen in this figure. The effects of sitosterolemia and ezetimibe on this pathway are shown as well. 
The Niemann-Pick C1-Like 1 (NPC1L1) transporter is present in the same cells and is responsible for cholesterol and phytosterol influx [3]. In patients with sitosterolemia, defective ABCG5/8 proteins reduce sterol and cholesterol excretion, thereby elevating serum concentrations. As a function of negative feedback, sitosterolemia patients have minimal HMG-CoA reductase activity and reduced endogenous cholesterol production [4]. This explains why the phytosterols lathosterol and desmosterol, surrogate markers of cholesterol synthesis, are usually decreased in sitosterolemia. Thus, dietary restriction of sterol intake and the selective NPC1L1 inhibitor ezetimibe are more effective than statins in reducing sterol levels.

The diagnosis of sitosterolemia requires its consideration first. This in some ways is the "rate limiting" step. Then, both a significant elevation in serum phytosterol concentrations and biallelic pathologic mutations in ABCG5/8 genes must be identified [5]. Around 100 cases of sitosterolemia have been described in the literature, with roughly 40 causative mutations discovered. Notably, a previously undescribed ABC transporter mutation (NM_022436.2:c.131T>A) was observed in our patient.

LDL-C levels are extremely variable among patients with sitosterolemia, making LDL-C an important but inadequate clue when considering the diagnosis [5,6]. Premature coronary atherosclerosis is the major cause of mortality, occurring as young as childhood. It is important to recognize, even emphasize, that coronary artery disease (CAD) risk in heterozygotes is also increased, and in a manner that is out of proportion to LDL-C elevation [7]. This is further evidence that phytosterols play an important and often unrecognized role in the genesis of atherosclerosis.

Although series from populations with high carrier rates for sitosterolemia-causing mutations suggest that heterozygotes do not have significant phytosterol elevations [7,8], our report adds to a list of published heterozygote cases who do have significant phytosterol elevations [6]. Given the high prevalence of heterozygosity relative to homozygosity for ABCG5/8 mutations, we believe that there may be a significant unmet need in identifying and appropriately treating these patients in order to diminish their cardiovascular risk [9].

Lastly, an easily overlooked but critical feature of our case highlights the importance of social determinants of health in providing quality cardiovascular care. Socioeconomic, cultural and religious factors, and inadequate access to health care can represent insurmountable barriers for patients needing highly specialized screening and surveillance [10]. It is not only important to render an accurate diagnosis; we must also be able to implement appropriate therapy. In our case report, though we have successfully diagnosed a rare disorder, we continue to try to ensure that the patient receives the care she needs.

\section{Conclusion}

A new sitosterolemia-causing mutation (NM_022436.2:c.131T >A) was discovered in this case. Additionally, significant elevations in serum phytosterols were identified in both heterozygote parents. This finding highlights an unrecognized increased risk of atherosclerotic disease in heterozygous carriers of sitosterolemia-causing mutations, and the need to identify and treat these not-so-rare individuals.

Disclaimers: The words expressed in the submitted article are original and have not been influenced by any institution or funding.
Source(s) of Support: No sources of support were used for the submitted article.

Disclosure: Drs. Seedat and Dasari have nothing to disclose and no financial conflicts of interest. Dr. Baum has consulted/served on advisory boards for Amgen, Madrigal, Sanofi, Merck, Allergan, and Esperion.

Acknowledgements: We thank Dr. Ernst J. Schaefer and Boston Heart Diagnostics for analysis of serum phytosterols. We thank Johanna Lora for technical assistance. We thank Vivian Bomie Lee and BomieArt for illustrative assistance.

\section{References}

1. Liebeskind A, Peterson AL, Wilson DP. Sitosterolemia in the Pediatric Population. [Updated 2020 Jan 16]. In: Feingold KR, Anawalt B, Boyce A, et al., editors. Endotext [Internet]. South Dartmouth (MA): MDText.com, Inc.; 2000-.

2. Mymin D, Salen G, Triggs-Raine B, et al. The natural history of phytosterolemia: Observations on its homeostasis. Atherosclerosis. 2018;269:122-128.

3. Wang J, Mitsche MA, Lutjohann D, et al. Relative roles of ABCG5/ABCG8 in liver and intestine. J Lipid Res. 2015;56(2):319-330.

4. Calandra S, Tarugi P, Speedy HE, et al. Mechanisms and genetic determinants regulating sterol absorption, circulating LDL levels, and sterol elimination: implications for classification and disease risk. J Lipid Res. 2011 Nov;52(11):1885-1926.

5. Peterson AL, DeLine J, Korcarz CE et al. Phenotypic Variability in Atherosclerosis Burden in an Old-Order Amish Family With Homozygous Sitosterolemia. JACC: Case Reports Volume 2, Issue 4, April 2020

6. Hidaka H, Nakamura T, Aoki T, et al. Increased plasma plant sterol levels in heterozygotes with sitosterolemia and xanthomatosis. J Lipid Res. 1990 May;31(5):881-888.

7. Horenstein RB, Mitchell BD, Post WS, et al. The ABCG8 G574R variant, serum plant sterol levels, and cardiovascular disease risk in the Old Order Amish. Arterioscler Thromb Vasc Biol. 2013 Feb;33(2):413-419.

8. Sehayek E, Yu HJ, von Bergmann $\mathrm{K}$, et al. Phytosterolemia on the island of Kosrae: founder effect for a novel ABCG8 mutation results in high carrier rate and increased plasma plant sterol levels. J Lipid Res. 2004 Sep;45(9):1608-1613.

9. Brinton EA, Hopkins PN, Hegele RA, et al. The association between hypercholesterolemia and sitosterolemia, and report of a sitosterolemia kindred. J Clin Lipidol. Jan-Feb 2018;12(1):152-161.

10. Havranek EP, Mujahid MS, Barr DA, Blair IV, Cohen MS, Cruz-Flores $S$ et al. Social Determinants of Risk and Outcomes for Cardiovascular Disease A Scientific Statement from the American Heart Association. Circulation. 2015 Sep 1;132(9):873-898. 
(c) ()

This work is licensed under Creative

Commons Attribution 4.0 License

To Submit Your Article Click Here: Submit Manuscript

DOI:10.31579/2641-0419/151
Ready to submit your research? Choose Auctores and benefit from:

* fast, convenient online submission

* rigorous peer review by experienced research in your field

* rapid publication on acceptance

* authors retain copyrights

* unique DOI for all articles

* immediate, unrestricted online access

At Auctores, research is always in progress.

Learn more www.auctoresonline.org/journals/clinical-cardiology-andcardiovascular-interventions 